is in encouraging a three-way dialogue between governments, the public and themselves, and concentrating their efforts on the national papers. But as he told a recent meeting of the American Association for the Advancement of Science, "scientists sometimes find it difficult to accept that the actual application of knowledge to the problems of society depends on a decision-making process normally situated at the government level."

\title{
Soviets climb down on mental hospital detentions
}

Sovier misuse of psychiatry as a means of political repression may be decreasing, according to Mrs Sofiya Kallistratova, a retired Moscow lawyer. Mrs Kallistratova, who in 1970 had defended General Petr Grigorenko, one of the most famous of the 'psychiatric dissidents' said recently that the forced hospitalisation of dissidents as being mentally ill was now being phased out in the major cities and in cases when the dissident in question was well-known. This change of policy, she explained, was the result of the protest campaign which has been waged incessantly over the last few years.

Within the Soviet Union, such protest is headed by the dissident "Working Commission for the Investigation of the Use of Psychiatry for Political Purposes', whose membership is said to include two psychiatrists who so far have remained anonymous. Since its foundation in autumn 1976, the 'Commission' has circulated a samizdat bulletin, listing cases of psychiatric repression; the latest issue (No. 9) of which also notes the arrest of Aleksandr Podrabinek, a member of the Commission.

Podrabinek is charged under Article 191 -of the Soviet Constitution, with having maliciously circulated libellous fabrications harmful to the Soviet state. The main 'evidence' against him is his authorship of a 265-page semizdat document Punitive Medicine, dealing with political abuses of psychiatry. (Podrabinek was, until his arrest, a paramedic working with an emergency ambulance unit, a means of conveyance often used for the hospitalisation of dissidents).

Under Soviet law, proof that the allegations contained in the document are true or were published in good faith would constitute a complete defence. Since the history of recent trials under Article 191 suggests that such proof would not be permitted to bc offered in court, a 'hearing' was called in London last week, to compile a dossier of defence evidence to be forwarded to the Soviet court and to be made available to relevant human rights organisations abroad.

The hearing, conducted by $\mathrm{Mr}$ Louis Blom-Cooper, Q.C. at the Institute of Advanced Legal Studies, called as 'witnesses' (either in person or via taped interviews) a number of pro- minent ex-dissidents-Vladimir Bukovskii, who first drew world attention to the problem of psychiatric abuse, Dr Marina Volkhanskaya, who refused to administer neuroleptic drugs to political 'cases', Leonid Plyushch and General Grigorenko, former victims of the abuses.

A less familiar figure at the hearing was Dr Yurii Novikov, a psychiatrist, recently arrived in the West, who formerly worked at the Serbskii Institute of Forensic Psychiatry, a body which exercises overall control of all forensic psychiatry in the Soviet Union. Dr Novikov made no claims to heroism, stating, for example, that when

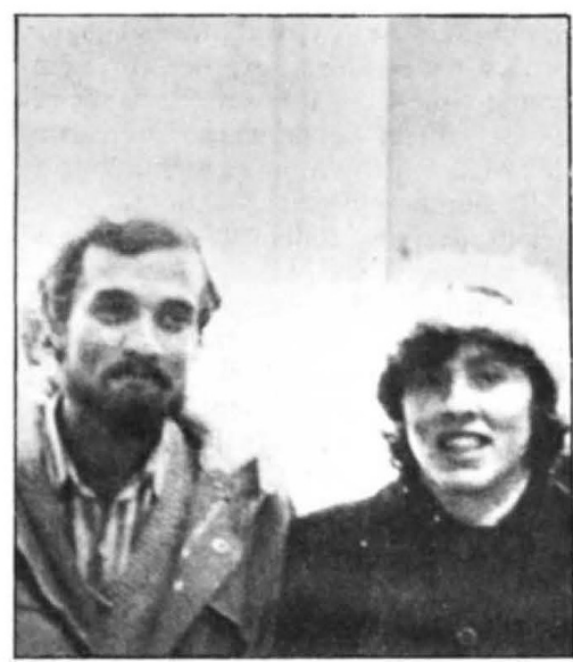

Podrabinek, now under arrest, and fellow dissident Irina Kaplun

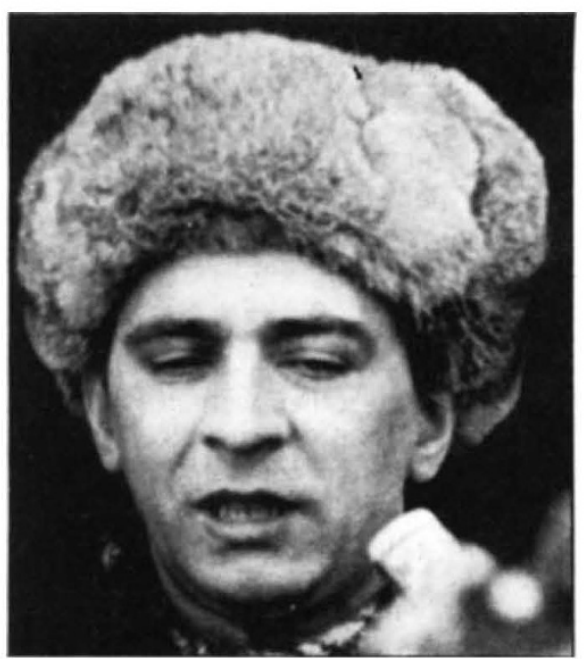

Leonid Plyuschch, speaking in Austria shortly after release from a Soviet mental hospital pressurised by a KGB official to certify a prisoner in a labour camp who was "making a nuisance of himself", he slid out of an awkward situation by suggesting that this was too complicated a case for him to decide, and recommended that the man be sent to the Serbskii Institute for a second opinion.

Perhaps because he makes no such claims for himself Dr Novikov's evidence is all the more credible. Certainly his 'inside' picture of Soviet forensic psychiatry is a frightening one. He asserts, for example, that one of the Assistant Ministers of Health, Evgenii S. Kuritsyn, who deals only with psychiatric matters, is a member of the KGB. He also gave a vivid account of the activity of Dr Georgii Morozov, a leading psychiatrist at the Serbskii Institute, to forestall criticism of Soviet psychiatry at the 1977 World Psychiatric Association Congressnotably by soliciting support from psychiatrists of the socialist bloc and from Finland.

Novikov's description of the Soviet pre-Honolulu campaign makes an ironic contrast to recent developments within the World Psychiatric Association. One of the results of Honolulu was the establishment of a committee to look into issues of professional ethics. Although the machinery for investigating such matters is still being worked out, there are suggestions that the committee might be set up in such a way that it is, by definition, totally ineffective. One informed source indicated to Nature that the WPA committee will not investigate any individual complaint of abuse; all such matters must be presented via the relevant national delegation. If implemented, such a situation would be worthy of Gilbert. A latterday PoohBah would appear before the Committee as both appellant (on behalf of the individual making the complaint) and defendant (on behalf of his country's psychiatric profession). One can only hope that this is a misreading of the situation, and that the WPA will adopt an Amnesty-like situation, where national delegations present complaints of abuse relating to countries other than their own. In the meantime, the Royal College of Psychiatrists is to set up its own body to study such complaints wherever they occut.

Vera Rich 